\title{
Cardiovascular Effects of Acrylic Bone Cement in Rabbits and Cats
}

\author{
D. PELLING, K. R BUTTERWORTH
}

British Medical fournal, 1973, 2, 638-641

\begin{abstract}
Summary
The cardiovascular responses to forcing acrylic bone cement, Plasticine, or soft paraffin wax into the medullary cavity of the femur have been studied in rabbits and cats. An acute fall in blood pressure, occurring within a few seconds of insertion, was demonstrated with each substance. In a few of the animals the blood pressure response had a second more protracted component and it is suggested that more than one mechanism is involved. The cardiovascular effects that have been observed in man when acrylic cement is used in prosthetic hip surgery also may be due to more than one mechanism.
\end{abstract}

\section{Introduction}

Acrylic cement has been found to be useful for providing a firm attachment of prosthetic devices to bone. Recently concern has been expressed about falls in blood pressure which occur when acrylic cement is used during prosthetic hip surgery (Frost, 1970; Ling and James, 1971; Phillips et al., 1971; Thomas et al., 1971; Ellis and Mulvein, 1972). Occasionally a profound hypotension occurred, which was followed by cardiac arrest (Burgess, 1970; Harris, 1970; Hyland and Robins, 1970; Powell et al., 1970; Cohen and Smith, 1971; Gresham et al., 1971; Thomas et al., 1971; Newens and Volz, 1972). It has been suggested that methylmethacrylate monomer diffuses from the cement into the circulation during setting and is responsible for the fall in blood pressure (Phillips et al., 1971; Ellis and Mulvein, 1972; Peebles et al., 1972). In support of this is evidence that when monomer labelled with ${ }^{14} \mathrm{C}$ was used in cement placed in the femur ${ }^{14} \mathrm{C}$ was detected in the blood both in dogs and in man (Homsy et al., 1972). Also, methylmethacrylate monomer lowers the blood pressure when injected intravenously in animals (Deichmann, 1941; Homsy et al., 1972; Peebles et al., 1972). However, there are surprisingly few published data which describe the effect on blood pressure of inserting acrylic cement into bone in animals (Homsy et al., 1969).

During surgery for total replacement of the hip in man it has been reported that the fall in blood pressure after insertion of the cement into the acetabulum was much less than that after the insertion into the femur (Charnley, 1970; Phillips et al., 1971; Thomas et al., 1971). This observation is difficult to explain on the basis of systemic monomer absorption which would be expected to occur from both these sites. The present paper describes an investigation in which acrylic cement, or control material containing no methylmethacrylate, was pushed into the medullary cavity of the femur in rabbits and cats. The results suggest that the leaching of components from the cement is not important.

\footnotetext{
British Industrial Biological Research Association, Carshalton, Surrey

D. PELLING, B.SC., PH.D., Experimental Physiologist

K. R. BUTTERWORTH, M.B., PH.D., Head of Toxicology
}

\section{Materials and Methods}

Seventeen New Zealand White rabbits of either sex, 2.4-4.4 kg body weight, were anaesthetized with intravenous pentobarbitone sodium ( $30 \mathrm{mg} / \mathrm{kg}$ body weight) and anaesthesia was maintained by additional doses of pentobarbitone sodium and ether. Six cats of either sex, $2 \cdot 2-4 \cdot 6 \mathrm{~kg}$ body weight, were anaesthetized with ether and anaesthesia was maintained by intravenous chloralose $(80-100 \mathrm{mg} / \mathrm{kg})$ or intravenous pentobarbitone sodium ( $30 \mathrm{mg} / \mathrm{kg}$, one cat). If fluctuations in arterial pressure were seen during surgery, these were minimized by deepening the anaesthesia before insertion of the cement. In some animals the injection of 2 to $3 \mathrm{ml}$ of $2 \%$ lignocaine (Xylocaine) into the tissues around the femur was necessary to abolish completely fluctuations in the blood pressure, which sometimes occurred on mechanical stimulation of the skin and muscle. In both species arterial blood pressure was recorded from the carotid artery, central venous pressure from the external jugular vein, respiratory movements using a mercury-inrubber strain gauge (Devices, Ltd.) around the thorax, and the rectal temperature using an electric thermometer (Light Laboratories). At intervals the E.C.G. was recorded at a faster paper speed using needle electrodes with standard limb lead II. Blood pressures were measured with Bell \& Howell transducers (Type 4-327-L221) and recordings made on a Devices multichannel recorder.

The upper part of the femur was exposed by detaching the muscles from the greater trochanter, which then was sawn off at about $45^{\circ}$ to the long axis of the bone. A burr-hole was made with a dental drill in the cut surface on the long axis of the bone. The hip joint itself was left intact. The medullary cavity was reamed to about two-thirds of its length with a 4-mm diameter drill. Acrylic cement (C.M.W. from C.M.W. Laboratories, Blackpool, or Surgical Simplex P from North Hill Plastics Ltd., London) was inserted as soon after mixing as the cement could be rolled between the fingers to form small plugs ( 2 to $4 \mathrm{~min}$ ). These were forced into the cavity with a length of 4-mm diameter flat-ended steel rod by applying an estimated pressure of about $500 \mathrm{lb} / \mathrm{in}^{2}\left(35 \mathrm{~kg} / \mathrm{cm}^{2}\right)$. Similar experiments were carried out using Plasticine (Harbutt's Plasticine Ltd., Bath) and pure paraffin wax (melting point $45^{\circ} \mathrm{C}$ ) (R. A. Lamb, London). Both have a similar consistency to cement in the workable state. Up to six insertions were made in each femur. In one of the rabbits acrylic cement was inserted into one femur and Plasticine into the other. In six experiments blood draining the femoral vein of the treated limb was conveyed by a $30-\mathrm{cm}$ length of polyethylene tubing (PP202, Portland Plastics Ltd., Kent) to the proximal end of the opposite femoral vein. The vein of the treated limb was cannulated at its proximal end near the inguinal ligament and the animals given 100 I.U. heparin $/ \mathrm{kg}$ intravenously. The shunt included a $\mathrm{T}$-junction for sampling.

Samples of lung, heart, kidney, and brain were fixed in $10 \%$ buffered formalin and frozen sections cut and stained with oil-red-O and Mayer's haemalum. The tissue sections were compared with similar sections prepared from untreated animals.

\section{Results}

There was no evidence of cardiovascular disturbance on placing plugs of cement, Plasticine, or paraffin wax into the opening in 
the femur. However, when either cement or control material was pushed into the medullary cavity with a steel rod there was an acute fall in arterial pressure both in the rabbits (fig. 1) and the cats (fig. 2).
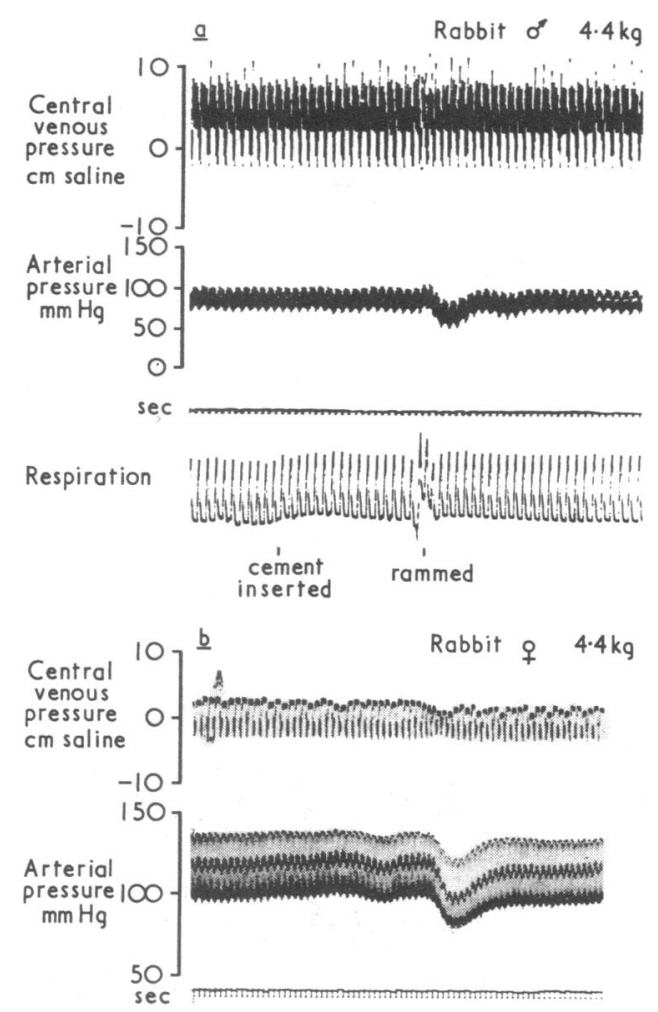

Respiration

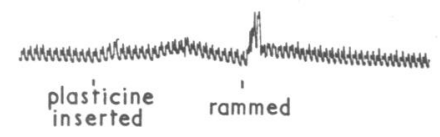

FIG. 1-Effects of pushing acrylic bone cement (A) or Plasticine (B) into femoral medullary cavity of rabbit.

A rise in central venous pressure often accompanied the fall in blood pressure in the cats, but in the rabbits there was sometimes a small fall in central venous pressure. Generally, little change was seen except in the experiments described later. There swere no consistent changes in the E.C.G. pattern. A rise in pulse rate occurred at maximum response in the cats but not in the rabbits. This was probably a baroreflex effect, since there was a negative correlation between the changes in systolic pressure and pulse rate with cement $(r=-0.441, P<0.05)$ and with Plasticine $(r=-0.643, P<0.001)$. A short period of apnoea sometimes accompanied, or more often followed, pushing the material into the femoral cavities of the cats (fig. 2) but this was not seen in the rabbits. The magnitude and time relations of the changes in blood pressure are shown in the table. All the effects could be produced by repeated insertions in the same femur.
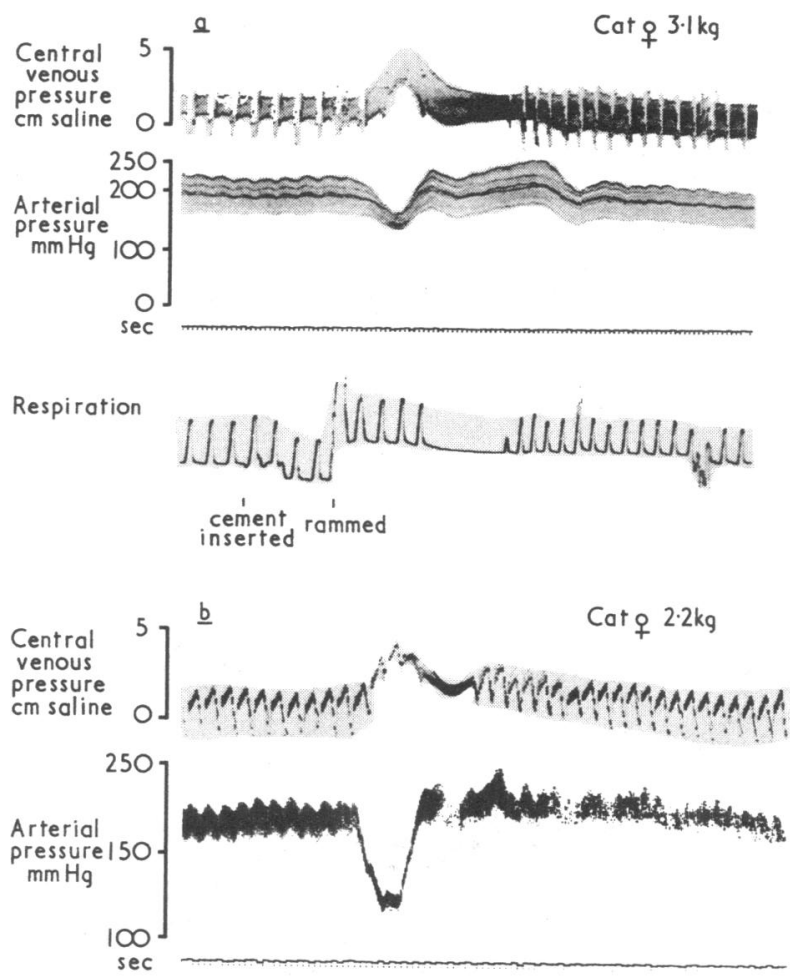

Respiration

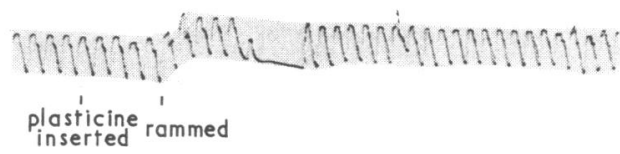

FIG. 2-Effect of pushing acrylic bone cement (A) or Plasticine (B) into femoral medullary cavity of cat.

Though the pattern and timing of the acute cardiovascular changes in the cat differed from those in the rabbit (figs. 1 and 2, table) it was clear that the control material produced essentially similar results to the acrylic cement in both species. In $11 \%$ of all the insertions in the rabbits a more complex cardiovascular disturbance occurred. The fall in blood pressure appeared to be composed of two phases; an acute fall, similar to that seen with the other insertions, followed by a second fall of variable duration, usually accompanied by a rise in central venous pressure and changes in respiration rate (fig. 3 ). In three experiments the arterial blood pressure failed to recover (fig. 3B). Sections of the lungs of these animals showed the presence of large amounts of fat and basophilic material in the pulmonary blood vessels (fig. 4). However, microscopical evidence of embolism was not confined to those animals which showed a protracted fall in blood pressure. Various amounts of embolic fat were seen in the lungs of both species, and though no attempt was made to assess objectively the degree of embolism in the entire pulmonary vascular bed, there was no obvious relation between the amounts of fat and the material inserted.

Arterial Blood Pressure Changes and Time Relations (means \pm S.E.) of the Acute Response which Followed Forcing Acrylic Cement, Plasticine, or Paraffin Wax into the Medullary Cavity of Femur

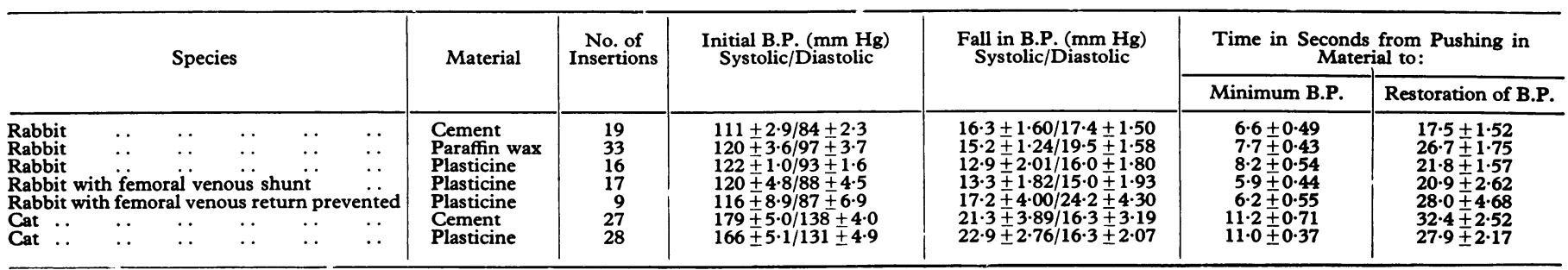




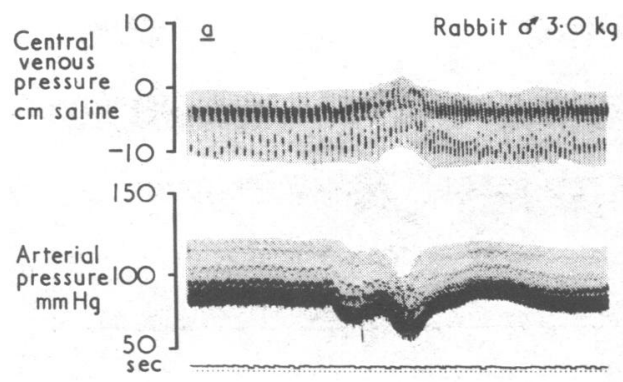

Respiration plasticine rammed

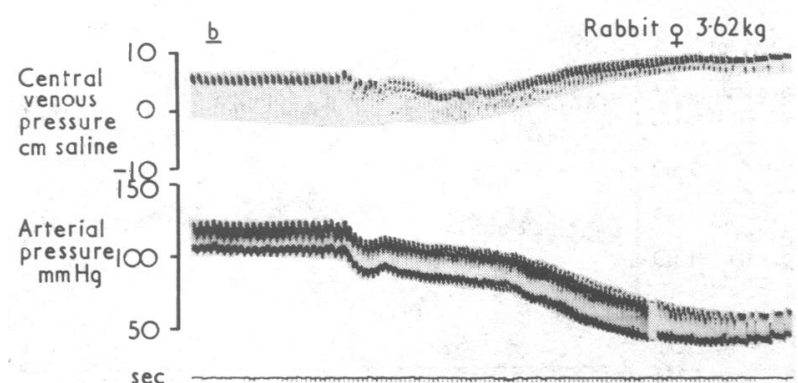

Respiration

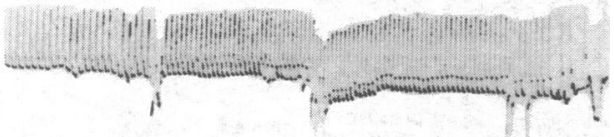

plasticine rammed

FIG. 3-Complex responses after pushing Plasticine into femoral medullary cavity of rabbit, (A) with and $(B)$ without recovery of arterial blood pressure.

In each of six rabbits with femoral venous shunts, pale coloured material, and in two experiments small air bubbles, were seen in the blood entering the shunt immediately after pushing Plasticine into the femur. This material was identified as clumps of fat and marrow cells. The longer venous return path in the shunt experiments did not delay the acute blood pressure response nor alter its magnitude (table). During the insertion of Plasticine in four experiments the femoral venous blood was prevented from entering the systemic circulation by drawing it through the side-arm of the shunt. This did not affect the acute blood pressure response (table). In one animal reinfusion of the blood produced a fall in arterial pressure and a rise in central venous pressure which persisted.

\section{Discussion}

There have been numerous reports describing cardiovascular complications after the use of acrylic bone cement in prosthetic hip surgery, but few attempts have been made to reproduce the effect in animals by methods simulating the operative conditions. The present paper describes a preparation which shows an acute fall in blood pressure when acrylic bone cement is forced into the femoral medullary cavity in two species and using different anaesthetic techniques. The medullary cavity of the femur was used since in prosthetic hip surgery the femoral insertion of cement has been reported to produce a greater hypotensive effect than the acetabular insertion (Charnley, 1970; Phillips et al., 1971; Thomas et al., 1971). A comparison of the time relations with published data indicates that the fall in pressure was similar to (Ling and James, 1971) or smaller than (Phillips
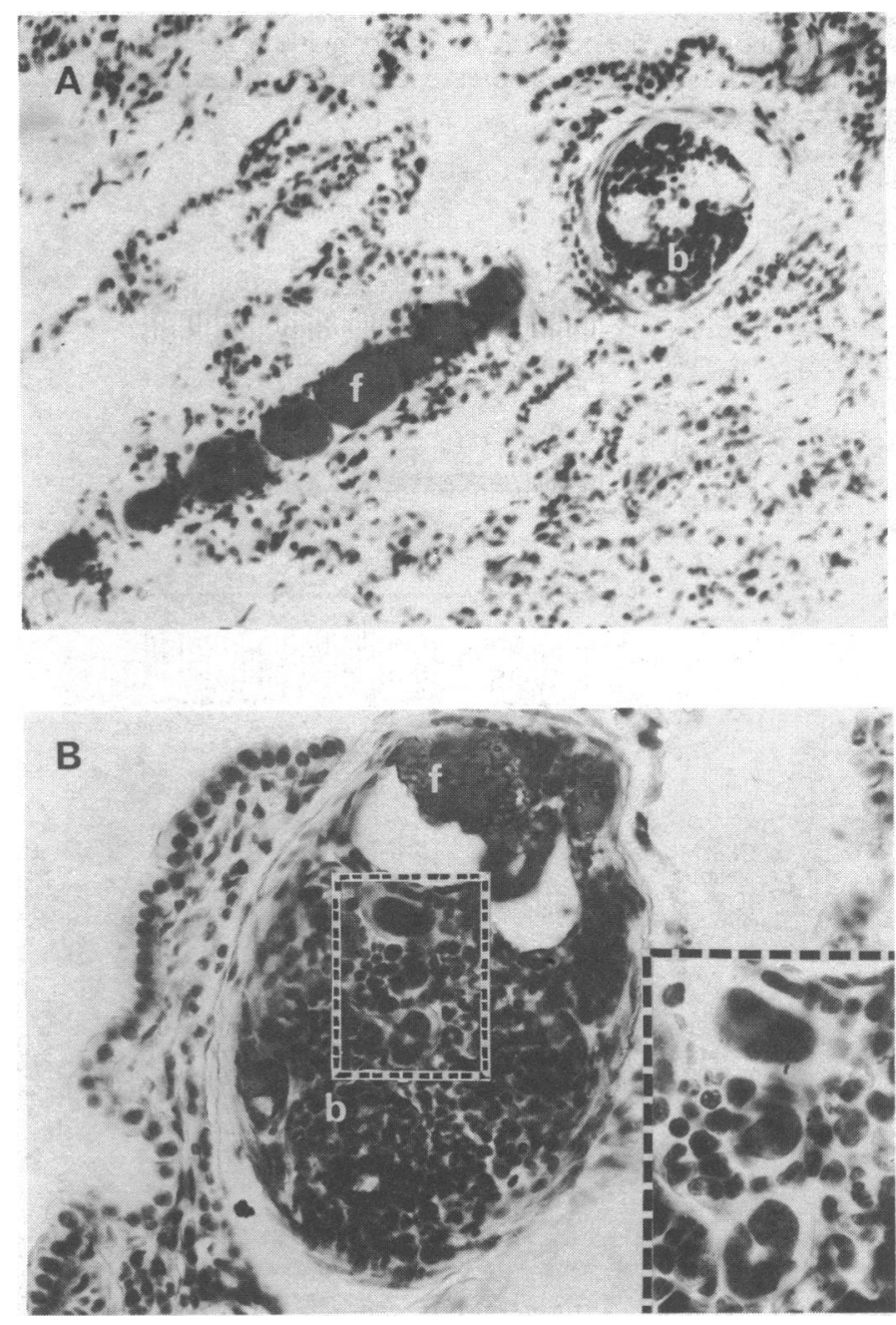

FIG. 4-Lung sections of a cat after insertion of acrylic cement into the medullary cavity of femur. (Oil-red-O and Mayer's haemalum.) A, Blood vessel cut longitudinally contains fat droplets (f), and that cut in transverse vessel cut longitudinally contains fat droplets (f), and that cut in transverse
section contains basophilic material (b) and also small fat droplets and section contains basophilic material (b) and also small fat droplets and
erythrocytes. ( $\times 10$ objective.) B, Another vessel containing basophilic erythrocytes. $(\times 10$ objective.) B, Another vessel containing basophilic
material. $(\times 25$ objective.) Inset: enlargement shows megakaryocyte-like cells indicating that material is probably bone marrow.

et al., 1971; Thomas et al., 1971) that in man, possibly occurred earlier, and was of shorter duration (Ling and James, 1971; Phillips et al., 1971; Thomas et al., 1971; Cadle et al., 1972). In the animal experiments each cardiovascular response followed a single thrust of the steel rod. In hip surgery a more prolonged fall or series of falls might be expected with ramming cement into the neck of the femur and impaction of the femoral head prosthesis.

The difference in the hypotensive responses after the femoral insertion as compared with the acetabular insertion of cement led Gresham et al. (1971) to suggest that it was the pressure of forcing the cement into the femoral cavity which was responsible rather than the cement itself. The observation that Plasticine or soft paraffin wax produced changes similar to those seen with cement supports this suggestion. Also it indicates that any systemic action of methylmethacrylate monomer carried away with the medullary venous blood, as suggested by Peebles et al. (1972), is small. However, the pressure developed in the medullary cavity depends on factors such as the force applied, the consistency of the material inserted, and the ease with which the contents can escape from the cavity. To confirm a relation between intramedullary and blood pressure changes, a satisfactory technique for monitoring the former in vivo is required. The finding of an effect with Plasticine and with wax is not consistent with the idea that the heat of polymerization of the cement plays a part (Frost, 1970). 
Our results are not in agreement with those of a recent investigation of the role of bone cement as a releasing factor for the genesis of fat embolism in cats (Dustmann et al., 1972). These workers also used Plasticine as a control substance and observed no haemodynamic disturbance when it was inserted. Details of the blood pressure changes were not given, but it was stated that in most cases when cement was inserted there was a fall in peripheral blood pressure and a rise in central venous pressure. Histological evidence of massive fat embolism was seen in the lungs in six out of eight experiments with cement and minimal fat embolism in all eight experiments with Plasticine. The reason for this difference in results is not known, though there were differences in operative and insertion techniques and in the anaesthetic agents used.

Several instances of cardiac arrest during or after insertion of the Thompson femoral head prosthesis in man were attributed to pulmonary fat embolism (Burgess, 1970; Dandy, 1971; Gresham et al., 1971) and a recent retrospective study identified this operation as entailing a special risk of death from this cause (Sevitt, 1972). The identification of fat and marrow cells in the femoral venous blood and lungs of a number of animals confirms the risk of embolism under experimental conditions. It is unlikely, however, that the acute hypotensive effect is caused by a factor carried in the blood since it occurred when the femoral venous return was prevented, and its onset was not delayed by the introduction of a $30-\mathrm{cm}$ shunt. A delay of at least five seconds would be expected on the basis of measurements of femoral venous flow. On four of the five occasions when blood was collected from the femoral vein draining the limb subjected to Plasticine insertion, there was no change in arterial pressure on reinfusion of this blood a few seconds later. In one experiment, however, there was a protracted fall in blood pressure accompanied by a rise in central venous pressure. The release of fat, marrow cells, or other materials into the circulation was a common occurrence judging from the histological examination of the lungs and femoral venous blood. Probably this was responsible for the occasional observations of protracted cardiovascular events, but the acute falls in blood pressure which occurred on almost every occasion may have been reflex in nature. The possibility should be considered that the hypotensive episodes which appear common after cement insertion in man (Harris, 1970; Ling and James, 1971; Phillips et al., 1971; Thomas et al., 1971) have a different pathogenesis from that leading to the relatively rare cases of cardiac arrest.

In conclusion, this animal preparation gives a reproducible acute fall in arterial blood pressure in circumstances similar to the operative situation in man and the results suggest that the mode of implantation is more important than the material implanted. Experiments ore in progress to further elucidate the nature of the depressor effect and the means of preventing it. These experiments will be reported in detail later.

We thank Dr. R. F. Crampton, Director of B.I.B.R.A., for his suggestions and comments on the paper. Also we are grateful to $\mathrm{Dr}$. P. Grasso for his opinion on the tissue pathology, and for his advice and encouragement.

\section{References}

Burgess, D. M. (1970). British Medical fournal, 3, 588.

Cadle, D., et al. (1972). British Medical fournal, 4, 107

Charnley, J. (1970). In Acrylic Cement in Orthopaedic Surgery. Edinburgh, Livingstone.

Cohen, C. A., and Smith, T. C. (1971). Anesthesiology, 35, 547.

Dandy, D. M. (1971). Injury, 3, 85.

Deichmann, W. (1941). Fournal of Industrial Hygiene and Toxicology, 23, 343.

Dustmann, H. O., Schulitz, K. P., and Koch, H. (1972). Archiv für orthopädische und Unfall-Chirurgie, $72,114$.

Ellis, R. H., and Mulvein, J. (1972). British Medical fournal, 2, 528.

Frost, P. M. (1970). British Medical fournal, 3, 524.

Gresham, G. A., Kuczynski, A., and Rosborough, D. (1971). British Medical Fournal, 2, 617.

Harris, N. H. (1970). British Medical fournal, 3, 523.

Homsy, C. A Tulios, H. S Anderson, M. S and Diferrante, N. M. (1969). Paper presented at Orthopaedic Research Society Meeting, New York, 17 January 1969. Cited by Charnley (1970).

Homsy, C. A., Tullos, H. S., Anderson, M. S., Diferrante, N. M., and King, J. W. (1972). Clinical Orthopaedics and Related Research, 83, 317.

Hyland, J., and Robins, R. H. C. (1970). British Medical fournal, 4, 176.

Ling, R. S. M., and James, M. L. (1971). British Medical fournal, 2, 404.

Newens, A. F., and Volz, R. G. (1972). Anesthesiology, 36, 298.

Peebles, D. J., Ellis, R. H., Stride, S. D. K., and Simpson, B. R. J. (1972) British Medical fournal, $1,349$.

Phillips, H., Cole, P. V., and Lettin, A. W. F. (1971). British Medical fournal, 3, 460 .

Powell, J.: N., McGrath, P. J., Lahiri, S. K., and Hill, P. (1970). British Medical fournal, 3, 326.

Sevitt, S. (1972). British Medical fournal, 2, 257.

Thomas, T. A., Sutherland, I. C., and Waterhouse, T. D. (1971). Anaesthesia, 26, 298.

\title{
"On-Off" Phenomena Related to High Plasma Levodopa
}

\author{
L. E. ClAveria, D. B. CALNE, J. G. ALLEN
}

British Medical fournal, 1973, 2, 641-643

\section{Summary}

The neurological deficit and plasma concentrations of levodopa have been studied in a Parkinsonian patient experiencing "on-off" phenomena. Blind evaluations of transient attacks of dysphonia revealed an association between episodes of neurological deterioration and exceptionally high plasma concentrations of levodopa shortly

\footnotetext{
Department of Medicine (Neurology), Royal Postgraduate Medical School, London W12 OHS

L. E. CLAVERIA, L.M.S., Research Fellow

D. B. CALNE, D.M., M.R.C.P., Consultant Neurologist

Roche Products Ltd., Welwyn Garden City, Herts

J. G. ALLEN, PH.D., B.SC., Senior Biochemist
}

after ingestion. These results indicate that "on-off" phenomena can be toxic reactions to levodopa rather than deteriorations due to inadequate intake or absorption of the drug. Management of patients subject to such attacks should be aimed at minimizing fluctuations in the serum level of the drug.

\section{Introduction}

Rapid spontaneous fluctuation of symptoms and signs has long been recognized as a characteristic feature of the Parkinsonian syndrome. The commonest manifestations are the exacerbations of tremor which occur when a patient is anxious and the transient episodes which suddenly freeze a patient to immobility when walking. Since the introduction of levodopa, oscillations in performance, often termed as the "on-off" effect or akinesia paradoxica, have been reported with increasing frequency (Cotzias et al., 1969; Barbeau et al., 1971; Barbeau, 1972; McDowell, 1972; Markham, 1972; Yahr, 1972; Damasio et al., 